\title{
The experimental survey on the rotary dryer performance: drying of wetted salt from effluent bio wastewater
}

\begin{abstract}
This work presents the effective optimum parameters of one rotary dryer such as energy consumption, optimum drying time, color and size distribution of outlet sodium chloride crystals from dryer and the amount of distilled water. The experimental results show, the maximum deviation between salt production in 12 minutes as drying time and production of dried saline crystals in 15.2 minutes is only $8 \%$ but since of the quality of outlet dried saline crystals is optimized in 15.2 minutes so this drying time is introduced as optimized time for drying. Also, the moisture content $(\mathrm{kg})$ per dried salt $(\mathrm{kg})$ in this condition is 0.005 . According to the literature, this amount of moisture content in outlet dried saline crystals is very suitable.
\end{abstract}

Volume 4 Issue 3 - 2017

\author{
Hossein Jafari, Farshad Farahbod \\ Department of Chemical Engineering, Islamic Azad University, \\ Iran
}

Correspondence: Farshad Farahbod, Department of Chemical Engineering, Islamic Azad University, Firoozabad, Iran, Email mf_fche@iauf.ac.ir

Received: May 10, 2017| Published: November 29, 2017

Keywords: salt crystals production, energy consumption, rotary dryer performance, optimum conditions

\section{Introduction}

The drying is a basic operation of enormous commercial importance in all industrial applications ranging through the food, agricultural, mining and even manufacturing sectors. ${ }^{1}$ Modern societies need better product quality, enhanced safety practices and more environmentally benign operations as well as higher productivity, better energy yield and reduced material wastage, also. ${ }^{2}$ As drying is certainly one of the most energy-intensive stages in factories, and as most dryers operate at low thermal yield, the development of experimental investigations offers an opportunity to improve dryer operation and efficiency consequently. The investigation of various types of dryers is very difficult due to the long time delay, which means that accidental variations in the input variables can damage the process for long periods of time before they are affected in the output variables. ${ }^{3,4}$ So, many surveys are required to remove such disturbances at an early stage., ${ }^{5,6}$ The majorities of investigations are experimental and deal with the average hold-up and drying time for the particle movement. Other types of particle movement take into account the cascade motion resulting from the lifting action of flights and the kiln action, simultaneously. ${ }^{7-9}$ In the some literatures the amount of size distribution of effluent $\mathrm{NaCl}$ crystals $^{5}$ and the air velocity of hot air $^{6}$ and ratio of feed per inlet hot air $^{8}$ is investigated. Thus the mechanistic models of rotary dryer distinguish between the flow of sodium chloride crystals in the dense phase and in the airborne phase. These later models forecast the drying time of solid crystals in each phase as well as its ideal throughput between over and under-loading conditions. On a factorial scale, after washing and centrifugation, salt crystals are dried, in most instances, in a counter-current stream rotary dryer. Transport of the salt crystals through the rotary dryer is affected by the slowly rotating shell. The slope of the rotary dryer helps the axial movement. ${ }^{10,11}$ Within the rotary dryer, the salt grains are lifted and showered through the hot air bulk by flights. The shape and appearance of which is adapted to the material being dried. Because of the complexity and variety of the movement of salt particles within the drum, the design or scale-up of rotary dryers is often a subject of skill and experience. The published manuscripts about drying process of salt crystals are so limited. ${ }^{12,13}$ Figure 1 shows rotary dryer as final stage in chemical process, schematically.

Since rotary dryers are optimally suited as drying for salt crystals, this type of dryer is considered. Also, the aim of this investigation is to improve the performance of rotary dryer as final stage in chemical process. The drying time, ratio of salt flow rate per hot air flow rate, occupied capacity of rotary dryer air, velocity of hot air and vaporization rate can be have major impacts on the color, size distribution and the amount of outlet dried salt crystals. So, this work have been perused major principles in performance of one rotary dryer supposed to production of dry salt crystals and also vaporization rate. Also, the amount of energy consumption is evaluated in each condition. Finally, major items which are effective on the dryer performance are evaluated in this paper.

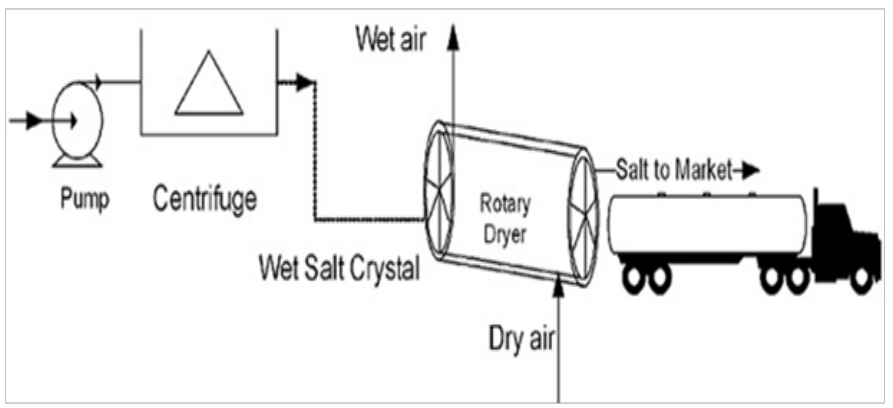

Figure I Schematic of rotary dryer which is used in chemical process.

\section{Materials and methods}

The wet salt crystals as feed resource passing through a rotating cylinder. The rotary dryer has a cylindrical shell. It is constructed from stainless steel plates and slightly inclined. Diameter and length of used rotary dryer is 0.5 meter and 2 meter, respectively. The studied rotary dryer rotates at $4 \mathrm{rpm}$. Salt as feed stream introduced at the upper end and moved towards the discharge end. 


\section{Results and discussion}

The main parameters are investigated in this paper.

\section{The effect of variations of drying time on quality of outlet dried salt}

Figure 2 shows the effect of drying time on quality of outlet dried salt. According to industrial data, size range $(0.7-0.8 \mathrm{~mm})$ for outlet dried sodium chloride crystals is so proper. The outlet saline crystals $(0.7-0.8 \mathrm{~mm})$ with same shape and uniform size are desirable for washing, filtering, transportation and storage. The Figure 2 is shown the size range distribution of outlet sodium chloride crystals from rotary dryer in optimum conditions $(1.5 \mathrm{~m} / \mathrm{sec}$ as hot air velocity and $15.2 \mathrm{~min}$ as drying time) is (680-805 micro meters). The outlet salt crystals have uniform shape and appearance, so are very desirable for the process such as washing, filtering, transportation and storage. The energy consumption is optimum comparing with the other ones and the color of outlet dried salt crystals will be white in the above conditions. These justifications are the other reasons to select the 1.5 $\mathrm{m} / \mathrm{sec}$ as hot air velocity and $15.2 \mathrm{~min}$ as drying time as optimum data.

\section{The effect of drying time on quantity of outlet dried salt crystals}

Figure 3 shows the effect of drying time on outlet saline flow rate. Considering the energy consumption and size range of outlet dried salt crystals from rotary dryer, the best drying time is 15.2 minutes. The amount of outlet dried salt crystals is 90kilo gram per hour when the drying time is 15.2 minutes. The color of outlet dried saline crystals from rotary is cream when the drying time is 30.5 minutes. Therefore, this drying time will be rejected. The maximum deviation between salt production in 12 minutes as drying time and production of dried saline crystals in 15.2 minutes is only $8 \%$ but since of the quality of outlet dried saline crystals is optimized in 15.2 minutes so this drying time is introduced as optimized time for drying. Also, the moisture content $(\mathrm{kg})$ per dried salt $(\mathrm{kg})$ in this condition is 0.005 . According to the literature, this amount of moisture content in outlet dried saline crystals is very suitable.

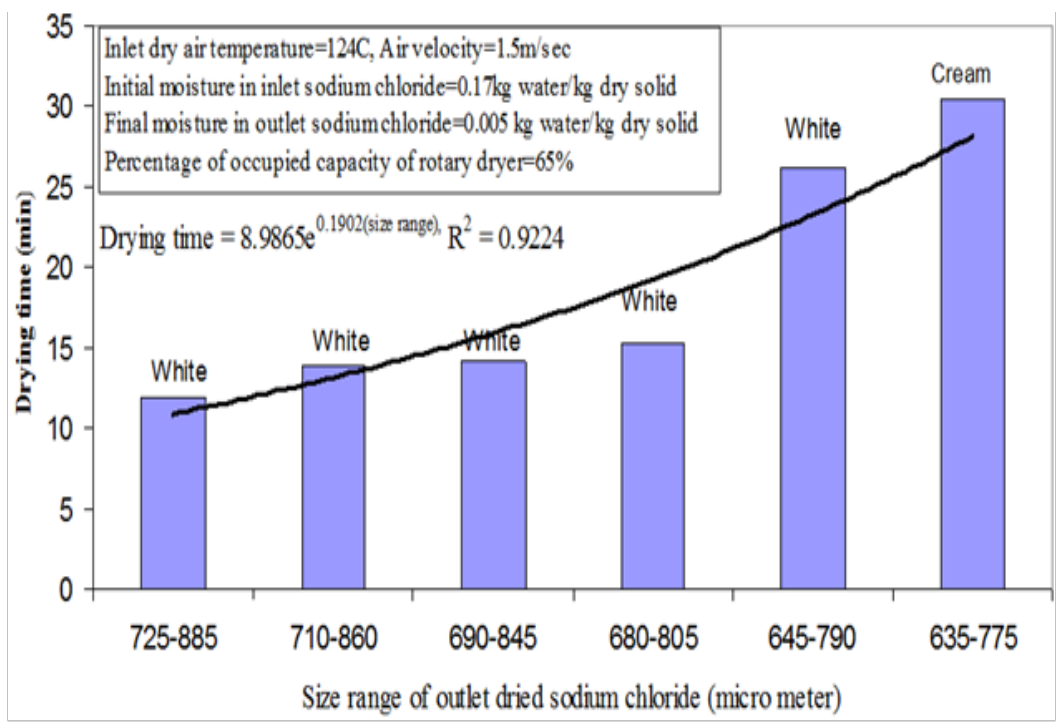

Figure 2 Variations of drying time on quality of outlet dried sodium chloride from rotary dryer.

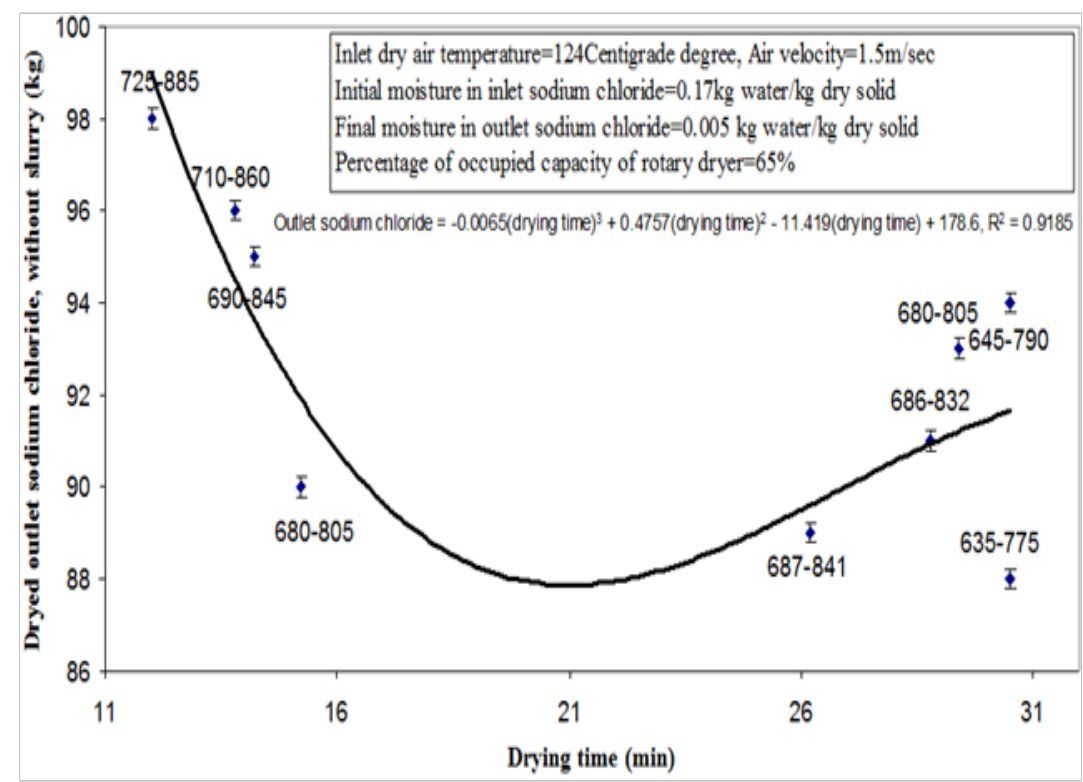

Figure 3 Drying time on quantity of outlet dried sodium chloride from rotary dryer. 
The experimental results in Figure 4 show there is a reverse relation between flow rates of outlet dried saline crystal from rotary dryer and the amount of energy consumption. The occupied volume of rotary dryer in this experiment is $60,65,70,75,80$ and 85 . So, the amount of dried outlet sodium chloride is increased. In Figure 4 the moisture content of outlet dried salt crystals changes from $0.0048 \mathrm{~kg}$ to $0.0075 \mathrm{~kg}$ of water per $\mathrm{kg}$ of dried salt crystals.

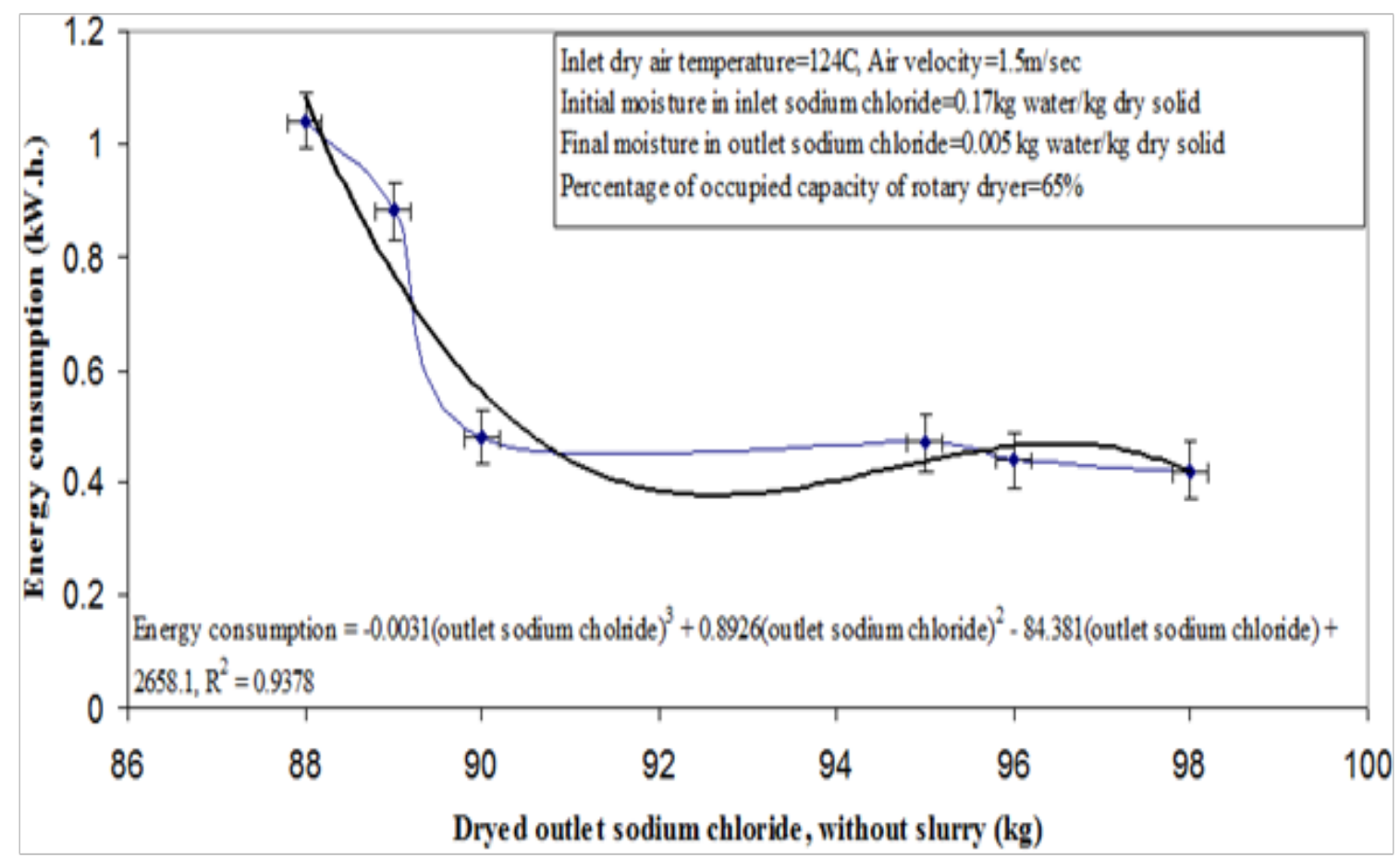

Figure 4 Relation between the flow rates of outlet dried saline crystals and the energy consumption.

\section{Conclusion}

Among of different types of dryers, rotary dryers are used for drying solid crystals such as sodium chloride. Therefore in this research this type of dryer is elected. Several independent variables are effective on rotary dryer performance. So, the major variables in performance of one rotary dryer are investigated in this experimental work. The experimental results show, the energy consumption is optimum comparing with the other ones and the color of outlet dried salt crystals will be white in the above conditions. Also, results show $1.5 \mathrm{~m} / \mathrm{s}$ is optimum hot air velocity and best drying time is $15.2 \mathrm{~min}$. In addition, the experimental results show, the maximum deviation between salt production in 12 minutes as drying time and production of dried saline crystals in 15.2 minutes is only $8 \%$ but since of the quality of outlet dried saline crystals is optimized in 15.2 minutes so this drying time is introduced as optimized time for drying. Also, the moisture content $(\mathrm{kg})$ per dried salt $(\mathrm{kg})$ in this condition is 0.005 .

\section{Acknowledgements}

None.

\section{Conflict of interest}

The author declares no conflict of interest.

\section{References}

1. Palzer S. Predicting drying kinetic and undesired agglomeration during drying of granules containing amorphous water-soluble substances in a continuous horizontal fluid bed dryer. Powder Technol. 2010;201(3):201212 .
2. Ericsson B, Hallmans B. Treatment of saline wastewater for zero discharge at the Debiensko coal mines in Poland. Desalination. 1996;105(12):115-123.

3. Mellmann J, Teodorov T. Solids transport in mixed-flow dryers. Powder Technol. 2011;205(1-3):117-112.

4. Nguyen PT, Hampton MA, Nguyen AV, et al. The influence of gas velocity, salt type and concentration on transition concentration for bubble coalescence inhibition and gas holdup. Chem Eng Res Des. 2012;90(1):33-39.

5. Farahbod F, Mowla D, Jafari Nasr MR, et al. Experimental study of forced circulation evaporator in zero discharge desalination process. Desalination. 2012;285:352-358.

6. Fezei R, Hammi H, Mnif A. Magnesium chloride precipitation from mixed salt solution using 1,4-dioxan. Chem Eng Res Des. 2011;89(3):367372.

7. Fan Geng, Zhulin Yuan, Yaming Yan, et al. Numerical simulation on mixing kinetics of slender particles in a rotary dryer. Powder Technol. 2009; 193(1):50-58.

8. Fan Geng, Yimin Li, Xinyong Wang, et al. Simulation of dynamic processes on flexible filamentous particles in the transverse section of a rotary dryer and its comparison with ideo-imaging experiments. Powder Technol. 2011;207(1-3):175-182.

9. Phongikaroon S, Bezzant RW, Simpson MF,. Measurements and analysis of oxygen bubble distributions in LiCl-KCl molten salt. Chem Eng Res Des. 2013;91(3):418-425.

10. Lee A, Sheehan ME. Development of a geometric flight unloading model for flighted rotary dryers. Powder Technol. 2010;198(3):395-403. 
11. Wormsbecker M, Ommen R, Nijenhuis $\mathrm{J}$, et al. The influence of vessel geometry on fluidized bed dryer hydrodynamics. Powder Technol. 2009;194(1-2):115-125.

12. Macedonio F, Katzir L, Geisma N, et al. Wind-Aided Intensified eVaporation (WAIV) and Membrane Crystallizer (MCr) integrated brackish water desalination process: Advantages and drawbacks. Desalination. 2011;273(1):127-135
13. Omar W, Chen J, Ulrich J. Reduction of seawater scale forming potential using the fluidized bed crystallization technology. Desalination. 2010;250(1):95-100. 